\title{
Op-Ed
}

The End of Naïve Europe, The Rise of Green Imperialism

\author{
Alberto Vázquez Ruiz
}

$\mathrm{O}$ n 29 September 2020, the European Commission officially launched the European Raw Materials Alliance (ERMA), a publicly supported "industrial alliance dedicated to securing a sustainable supply of raw materials in Europe". The announcement amounts to the firing of a starting pistol for a publiclyfunded race to explore and extract mineral deposits outside the European Union and especially within its borders.

Previously, the EU only financed private mining and metallurgical companies under the pretext of improving technological innovation and market competition. Since the launch of Horizon 2020 in 2014, the Commission has assembled the institutional tools (e.g. EIT Raw Materials, the Partnership Instrument) to finance private technology developments inside the EU for exploration, exploitation and metallurgy. Horizon 2020 is ending this year, but its financing instruments will remain, although the justification of technological innovation seems no longer necessary.
CRITICAL RAW MATERIALS RESOURCES POTENTIAL IN THEEU

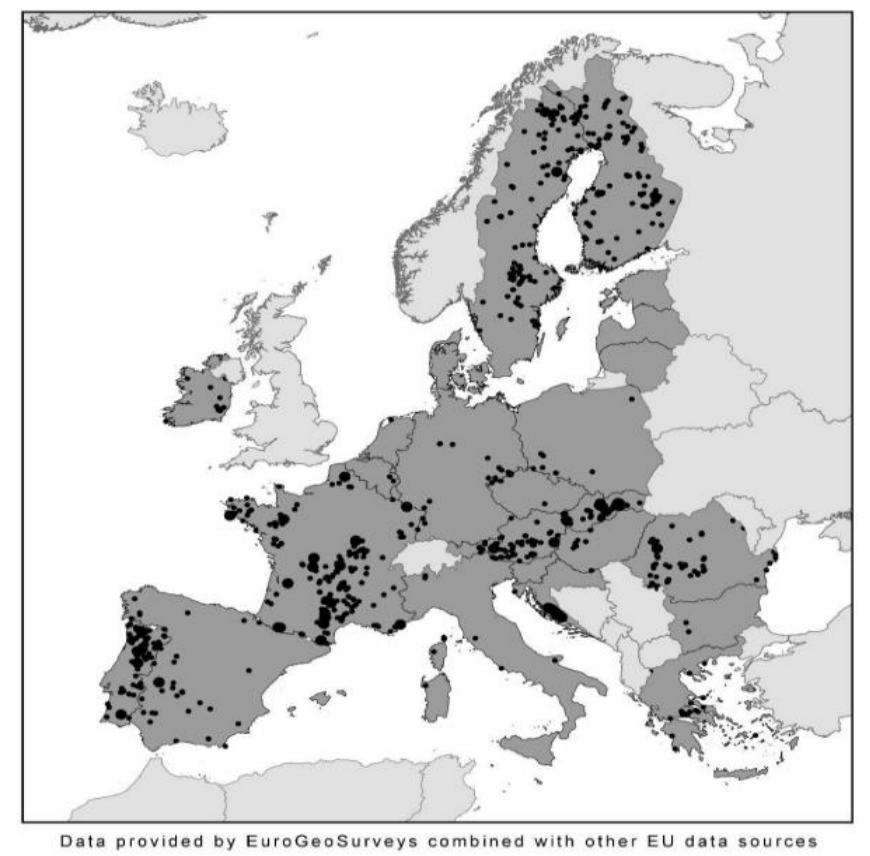

Image: CRM deposits EU-27 (2020).

Source: European Commission's M(2020)

Correspondence:

Alberto Vázquez Ruiz, alberto.vazquez@,catapa.be

Cite this article:

Vázquez Ruiz, A. 2020. “Op-Ed: The End of Naïve Europe, The Rise of Green Imperialism.” Commodity Frontiers 1: 56-59. doi: 10.18174/cf.2020a17975.

Commodity Frontiers is an open-access journal edited by the CFI Editorial Board, Mindi Schneider, senior editor. Read it online at Commodity Frontiers, or our website, commodityfrontiers.com.

This work is licensed under a Creative Commons Attribution-NonCommercial 4.0 International License.

\section{(1) (8)}


"The era of a naïve Europe that solely relies on soft power is behind us." With these words, Internal Market Commissioner, Thierry Breton, announced earlier this month the "EU action plan for critical raw materials." This is the EC's strategy for facing the consequences of the commercial war between the USA and China, embedded in the context of COVID-19.

While the COVID-19 pandemic has indeed created the perfect conditions for rallying support for this industry, it is well-known that resource extraction and its processing together represent $90 \%$ of biodiversity loss and water stress in the world.

What's more, it is impossible for the EC to ignore last year's report by the International Resources Panel (UNEP), which clearly warned humanity that metal extraction and production doubled health and climate change impacts from 2000 to 2015 solely. And today, mining and metallurgy already represent $20 \%$ of all health impacts from air pollution and more than a quarter of global carbon emissions. So why is the Commission making this change of course?

Behind the shift in position is the justification that "access to resources is a strategic security question for making the green and digital transformations a success". Although the Commission claims to share the widespread willingness in Europe to combat climate change and leave no person and no place behind in the process, it openly calls for an increased mining boom which will reinforce pressing systemic problems on people and planet.

While green technologies are based on energy sources which are renewable, their machines are not. Generators for solar, eolic (wind), and tidal energy rely on metals (many metals if you consider off-grid technologies). The planned transition to a "green economy" without socio-economic restructuring that pushes for a drastic reduction in energy consumption will simply move us from an energy matrix based on the extraction and combustion of fossil fuels towards a loop of increasing extraction and processing of metals for the manufacturing of metal-based solutions.

It could be argued that a society based on metal-based technologies is a sustainable scenario, since we could recycle these elements in the future. But the reality is very far less rosy. The IRP-UNEP also warned us that "only 18 metals have recycling rates higher than $50 \%$ ". For the rare earths elements (REEs) needed in most green energy technologies, the recycling rate is $\mathbf{1 \%}$. What will happen in 30 years when today's new renewable energy-generating machines are already obsolete and fossil fuels are no longer efficient for extraction? Mining, metallurgy and manufacturing industries are the biggest energy consumers. "What is happening today is nothing less than a massive PR campaign to sell the idea that mining is not only necessary, but it can also be sustainable," said Nick Meynen, Policy officer at the European Environmental Bureau (EEB).

While the EC's Action Plan does recognise the need to improve recycling rates and the importance of reinforcing the circular economy, it lacks a coherent set of proposals that could tackle the reasons behind low recycling rates and the slow implementation of a circular economy. There are no regulations for recyclability (including no restrictions for production, materials are mixed in a way that makes products poorly recyclable, but cheaper - it is not simply an end-of-use technological 
issue), repairability (modularity in products and end of the monopoly on spare parts production) or reusability (plans on how to proceed with older machines).

\section{I} nternal Market Commissioner Breton recognises that the "post-war world architecture is faltering." The proposed treatment in the form of ERMA, however, seems to confuse the disease with the cure. Rather than rebuilding our strained political, economic, social, and ecological systems, ERMA will contribute to and even accelerate their decline by failing to recognize root causes. The Alliance and its action plans can be seen as both a symptom of political negligence, and a part of a more complex agenda towards green imperialism.

\section{Europe has expressed its aim to become the green energy superpower. However,} the quantity of minerals that the EC considers necessary for this future transition is extreme, even as global metal demand already increased by $87 \%$ from 1980 to 2008. "Critical raw materials" (a technopolitical rebranding of the elements the EC considers necessary today) are increasingly demanded for batteries in electric vehicles, off-grid generation and storage, and other "green" uses. Fulfilling these resource demands is simply impossible without pushing social peace to its limits, inside and outside the EU.

As reported in 2018 by the International Institute for Sustainable Development (IISD), "the transition to a low-carbon economy - and the minerals and metals required to make that shift - could affect fragility, conflict and violence dynamics in mineral-rich states". A similar and more straight-forward analysis was made by the EEB that year: "More mining leads to more fighting". This is the reality that local communities and civil society organisations are facing all around the world. Global Witness has even named mining as the sector most responsible for the killing of land and environmental defenders across the globe. While this reality has been commonly associated with the Global South, the Due Diligence voluntary process supported by the EU to guarantee responsible sourcing of metals is far from being useful to avoid human rights violations.

Now, in the middle of the COVID-19 crisis, Europe seeks to compensate its weaker commercial share in raw materials, and to reinforce its aim to secure supplies, through insourcing. Breton mentions that the Action Plan seeks to "protect our democracies against the menace of disinformation", but at the same time points out that the major barrier to developing insourcing is a lack of "public acceptance" in Europe to allow new mining projects. Therefore, many EC financed research projects have been looking for increasing "public acceptance" for this sector in local communities across the European Union affected by proposed and/or operating extractive projects.

There is still no democratic capacity for local communities and municipalities to makes decisions about allowing mining projects that will drastically change their land and very possibly leave tonnes of reactive waste in their wake. The discourse of the EC is that there is a lack of understanding of the mining sector by local communities and that there is a need to educate Europeans on the current reality of the mining sector (a false mantra by the sector is that the environmental issues of mining and metallurgy are a matter of the past). The discourse mixes the real needs of 
our planet with the demand for resources enshrined in the Commission's plans for an ominous green EU. Localities are asked to sacrifice their water, land, environments and people in service of Europe's future.

"By building, today, the foundations of tomorrow's autonomy, our Continent has the opportunity to establish a set of rules, infrastructures and technologies that will make it a powerful Europe, without ostracism or discrimination", states

Breton. This sentence provides an insight into the future the Commission is constructing in Europe. A "powerful Europe" directed by the privileged few living in Europe's main cities and enjoying access to green energy, but a nightmare of inequality for local communities around the world that will be negatively impacted by the increasing environmental, social and political issues on which the Green Empire will rely. To prevent this upcoming reality, many organisations today state "We can't mine our way out of the climate crisis".

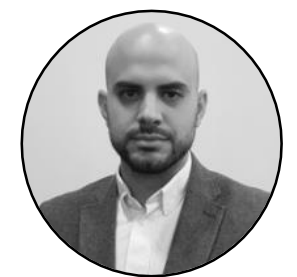

Alberto Vázquez Ruiz holds a MSc. in Conflict and Development (UGent, Belgium) and is specialized in topics related to mining and electronics. Since May 2018 he has been Project Coordinator at CATAPA (Belgium), researching on metal supply chains, on socio-environmental impacts of mining operations on local communities and on extractive waste in the EU. 